\title{
Nonneoplastic Cystic Lesions of the Central Nervous System-Histomorphological Spectrum: A Study of 538 Cases
}

\author{
Anusha S. Bhatt ${ }^{1}$ Radhika Mhatre ${ }^{1}$ Bevinahalli N. Nandeesh ${ }^{1}$ Anita Mahadevan ${ }^{1}$ \\ T. Chickabasaviah Yasha ${ }^{1}$ Vani Santosh ${ }^{1}$
}

${ }^{1}$ Department of Neuropathology, National Institute of Mental Health and Neurosciences (NIMHANS), Bengaluru, Karnataka, India

\begin{abstract}
Address for correspondence Bevinahalli N. Nandeesh, MD, Department of Neuropathology, National Institute of Mental Health and Neurosciences (NIMHANS),Bengaluru 560 029, Karnataka, India (e-mail: nandeeshbn@gmail.com).
\end{abstract}

\begin{abstract}
Background A wide spectrum of non-neoplastic cystic lesions can occur in the central nervous system (CNS). These are uncommon, benign and of diverse aetiology, pathogenesis and clinical presentation. The spectrum of these lesion varies based on the location and in turn histogenesis.

Objectives To evaluate the pathologic spectrum of non-neoplastic cystic lesions in the CNS (both developmental and acquired) and highlight the role of histopathology in the diagnosis of these cystic lesions.

Settings and Design This was a retrospective study done at Department of Neuropathology, NIMHANS.

Materials and Methods All the histologically diagnosed non-neoplastic cystic lesions of CNS submitted to the Department of Neuropathology between 2014 and 2017 were reviewed in this study. The data was analysed in relation to the type of cysts, location (intracranial and spinal), and clinical profile using SPSS software version 17.0.

Results The study included 538 cases with patient age ranging from 5 months to 90 years [M:F:1:1.05]. Non-infective cysts (489/538, 90.8\%) predominated over the infec-

Keywords

- central nervous system

- infective

- noninfective

- nonneoplastic cysts tive cysts $(49 / 539,9.2 \%)$ with epidermoid cysts $(132 / 538,24.5 \%)$ being the most frequent one followed by colloid cysts $(126 / 538,23.4 \%)$ and arachnoid cysts $(111 / 538$, $20.6 \%)$. The most common infective cyst was neurocysticercosis $(42 / 538,7.8 \%)$ followed by hydatid cyst $(7 / 538,1.3 \%)$. Intracranial cysts $(415 / 538,77.1 \%)$ were more common than spinal ones (123/538, 22.9\%). Conclusions: A variety of cystic lesions occur in the CNS with overlapping clinical features, image findings and lining. Hence, histological analysis plays a crucial role in the evaluation of these lesions.
\end{abstract}

\section{Introduction}

A wide spectrum of nonneoplastic cystic lesions can occur in the central nervous system (CNS). These are uncommon, most often benign, and of diverse etiology, pathogenesis, and clinical presentation. Advances in diagnostic neuroimaging have facilitated early recognition and diagnosis.
However, accurate diagnosis of the nature of cyst is usually difficult due to overlapping features between neoplastic and nonneoplastic cysts. Classifications and terminology schemes used by pathologists, neurosurgeons, and neuroradiologists have always been nonuniform and inconsistent. Hence, there is no established classification system for the same. 
Many of these cystic lesions are developmental in nature, while others are acquired. ${ }^{1}$ They have a good prognosis which may recur as a result of incomplete removal. There is a limited comprehensive study of all nonneoplastic cystic lesions of CNS from India, with majority of them having the studied mainly, the developmental cysts. In this study, we evaluate the pathologic spectrum of cystic lesions in the CNS and highlight the role of histopathology in the diagnosis of these cystic lesions. This is the largest series studying all the nonneoplastic cystic lesions of the CNS, both developmental and acquired.

\section{Materials and Methods}

All the histologically diagnosed nonneoplastic cystic lesions of CNS, submitted to the department of neuropathology between 2014 and 2017, were reviewed in this study. The demographic data and clinical profile were retrieved from our records. All neoplastic cystic lesions were excluded. The slides were reviewed and special stains performed when necessary. The data were analyzed in relation to the type of cysts, location (intracranial and spinal), and clinical profile.

\section{Results}

The study reviewed a total of 538 histologically confirmed nonneoplastic cystic lesions of CNS. The age range was from 5 months to 90 years (mean, $31.9 \pm 16.8$ years) with no gender predilection (male:female ratio $=1: 1.05$; - Table 1) .

Of these, noninfective $(489 / 538,90.8 \%)$ were more frequent than infective (49/538, 9.2\%). Epidermoid cysts (132/489, 26.9\%) were the most frequent among the noninfective group, followed by colloid cysts (126/489, 25.7\%) and arachnoid cysts $(111 / 489,22.7 \%)$. The infective cysts included neurocysticercosis $(42 / 49,85.7 \%)$, followed by hydatid cyst (7/49, 14.2\%; - Table $\mathbf{1})$.

The epidermoid cysts were the most common constituting $24.5 \%$ of the nonneoplastic cystic lesions. Mean age at presentation was 33.37 years with no gender predilection. The most common site for epidermoid cysts was cerebellopontine angle (43.2\%), followed by ventricular system (14.4\%), cerebral hemispheres (12.9\%), and spinal location (9.8\%). In the ventricular system, fourth ventricle (36.8\%) was the most common location, followed by prepontine cistern (26.3\%). With the cerebral hemispheres, temporal lobe $(52.9 \%)$ was the most common, followed by frontal lobe (23.5\%). Intraspinal cysts were most frequent in lumbar and sacral location (38.4\% each; - Table 2). Histologically, the cysts had characteristic lining by keratinizing stratified squamous epithelium with lumen filled with acellular lamellated keratin ( - Fig. 1A). Xanthogranulomatous response was noted in three of the cases, and abscess formation was noted in two of them secondary to rupture and release of cyst contents.

Colloid cysts were the second most common (23.4\%; mean age: $34.7 \pm 14.8$ years). No gender predilection was noted. Majority were located in the third ventricle $(98.4 \%)$, with two in lateral ventricles ( $\boldsymbol{- T a b l e ~} \mathbf{2}$ ). These cysts were lined by cuboidal to columnar epithelium with colloid-like material in the lumen ( - Fig. 1C). Xanthogranulomatous response was noted in eight of the cases.

The arachnoid cysts were more commonly located in the spine $(41.5 \%)$, followed by hemispheric location $(22.5 \%)$. Majority were in the lumbar region (69.5\%; - Table 2). The cyst wall was collagenous and lined by flattened arachnoidal cells ( - Fig. 1D). The mean age of the patients was $29.5 \pm$ 18.2 years. No gender predilection was noted.

Dermoid cysts were frequent in the intraspinal location (51.5\%; $58.8 \%$ in thoracic and $41.1 \%$ in lumbar). In the intracranial compartment, hemispheric location was the most common, followed by posterior fossa, anterior cranial fossa base, and pineal region (-Table 2). These cysts were morphologically similar to the epidermoid cysts, except for additional presence of hair shafts (-Fig. 1B). The mean age at presentation was 22.24 years with a male preponderance (male:female ratio $=2 \cdot 2: 1$ ).

Table 1 Age and sex distribution of nonneoplastic cysts of the central nervous system

\begin{tabular}{|c|c|c|c|c|c|}
\hline Nature of cyst & Subtype & $\begin{array}{l}\text { Total number of } \\
\text { cases, } n(\%)\end{array}$ & Male:female ratio & Age range $(y)$ & Mean age $(y)$ \\
\hline \multirow{10}{*}{$\begin{array}{l}\text { Noninfective } \\
(489 / 538,90.8 \%)\end{array}$} & Epidermoid cysts & $132(24.5)$ & $1.04: 1$ & $3-64$ & 33.37 \\
\hline & Colloid cysts & $126(23.4)$ & $1: 1.05$ & $9-90$ & 34.7 \\
\hline & Arachnoid cysts & $111(20.6)$ & $1.01: 1$ & 5 months -66 & 29.5 \\
\hline & Dermoid cysts & $33(6.1)$ & $2.2: 1$ & $2-54$ & 22.24 \\
\hline & Rathke's cleft cysts & $29(5.6)$ & $1: 1$ & $12-77$ & 43.03 \\
\hline & Neurenteric cysts & $26(4.8)$ & $2.25: 1$ & $2-74$ & 23.5 \\
\hline & Benign cystic lesions, $n$ & $11(2.0)$ & 2.3:1 & $3-66$ & 32.7 \\
\hline & Glioependymal/glial cysts & $10(1.9)$ & $2.3: 1$ & $\begin{array}{l}6 \text { months }-59 \\
\text { years }\end{array}$ & 14.35 \\
\hline & Tarlov's cysts/perineural cysts & $8(1.5)$ & $1.6: 1$ & $21-75$ & 42.6 \\
\hline & Porencephalic cysts & $3(0.6)$ & $1: 2$ & $5-34$ & 21.33 \\
\hline \multirow{2}{*}{$\begin{array}{l}\text { Infective } \\
(49 / 538,9.2 \%)\end{array}$} & Neurocysticercosis & $42(7.8)$ & $1.2: 1$ & $6-68$ & 33.8 \\
\hline & Hydatid cysts & $7(1.3)$ & $1: 1.3$ & $10-48$ & 27.4 \\
\hline
\end{tabular}


Table 2 Location of noninfective central nervous system cysts

\begin{tabular}{|c|c|c|c|}
\hline Type of cysts & Number of cases & Location & No. of cases \\
\hline Epidermoid cysts & 132 & & \\
\hline \multirow[t]{10}{*}{ Intracranial } & \multirow[t]{10}{*}{$121 / 132$} & Parenchymal & 17 \\
\hline & & Suprasellar & 6 \\
\hline & & Ventricular & 19 \\
\hline & & Interhemispheric & 10 \\
\hline & & MCF base & 5 \\
\hline & & Corpus callosal & 1 \\
\hline & & Posterior fossa & 3 \\
\hline & & Tentorium & 1 \\
\hline & & Brainstem & 2 \\
\hline & & CP angle & 57 \\
\hline \multirow[t]{3}{*}{ Spinal } & \multirow[t]{3}{*}{$13 / 132$} & Thoracic & 3 \\
\hline & & Lumbar & 5 \\
\hline & & Sacral & 5 \\
\hline Dermoid cysts & 33 & & \\
\hline \multirow[t]{4}{*}{ Intracranial } & \multirow[t]{4}{*}{$15 / 33$} & Posterior fossa & 5 \\
\hline & & ACF base & 2 \\
\hline & & Pineal gland & 1 \\
\hline & & Parenchymal & 7 \\
\hline \multirow[t]{2}{*}{ Spinal } & \multirow[t]{2}{*}{$17 / 33$} & Thoracic & 10 \\
\hline & & Lumbar & 7 \\
\hline \multirow[t]{2}{*}{ Colloid cyst } & \multirow[t]{2}{*}{126} & Third ventricle & 124 \\
\hline & & Lateral ventricle & 2 \\
\hline Arachnoid cysts & 111 & & \\
\hline \multirow[t]{8}{*}{ Intracranial } & \multirow[t]{8}{*}{$65 / 111$} & Suprasellar & 10 \\
\hline & & Parenchymal & 25 \\
\hline & & Ventricular & 7 \\
\hline & & Pineal & 1 \\
\hline & & Posterior fossa & 12 \\
\hline & & CP angle & 8 \\
\hline & & Brainstem & 1 \\
\hline & & Basal ganglia & 1 \\
\hline \multirow[t]{4}{*}{ Spinal } & \multirow[t]{4}{*}{$45 / 111$} & Cervical & 5 \\
\hline & & Thoracic & 32 \\
\hline & & Lumbar & 6 \\
\hline & & Sacral & 2 \\
\hline Rathke's cleft cysts & 30 & Sella-suprasellar & 30 \\
\hline Neurenteric cysts & 26 & & \\
\hline \multirow[t]{3}{*}{ Intracranial } & \multirow[t]{3}{*}{$5 / 26$} & Prepontine & 2 \\
\hline & & Ventricular & 2 \\
\hline & & CP angle & 1 \\
\hline
\end{tabular}


Table 2 (continued)

\begin{tabular}{|c|c|c|c|}
\hline Type of cysts & Number of cases & Location & No. of cases \\
\hline \multirow[t]{6}{*}{ Spinal } & \multirow[t]{6}{*}{$21 / 26$} & Craniovertebral junction & 2 \\
\hline & & Cervical & 7 \\
\hline & & Thoracic & 5 \\
\hline & & Lumbar & 4 \\
\hline & & Sacral & 1 \\
\hline & & Site not specified & 2 \\
\hline Tarlov's cyst & 8 & & \\
\hline \multirow[t]{2}{*}{ Spinal } & \multirow[t]{2}{*}{$8 / 8$} & Lumbar & 2 \\
\hline & & Sacral & 6 \\
\hline Porencephalic cyst & 3 & Lobar & 3 \\
\hline \multirow[t]{6}{*}{ Glioependymal/glial/ependymal cysts } & \multirow[t]{6}{*}{10} & Ventricular & 4 \\
\hline & & Cerebellum & 2 \\
\hline & & CP angle & 1 \\
\hline & & Suprasellar & 1 \\
\hline & & Septum pellucidum & 1 \\
\hline & & Lobar & 1 \\
\hline
\end{tabular}

Abbreviations: MCF, middle cranial fossa; ACF, anterior cranial fossa; CP, cerebellopontine.

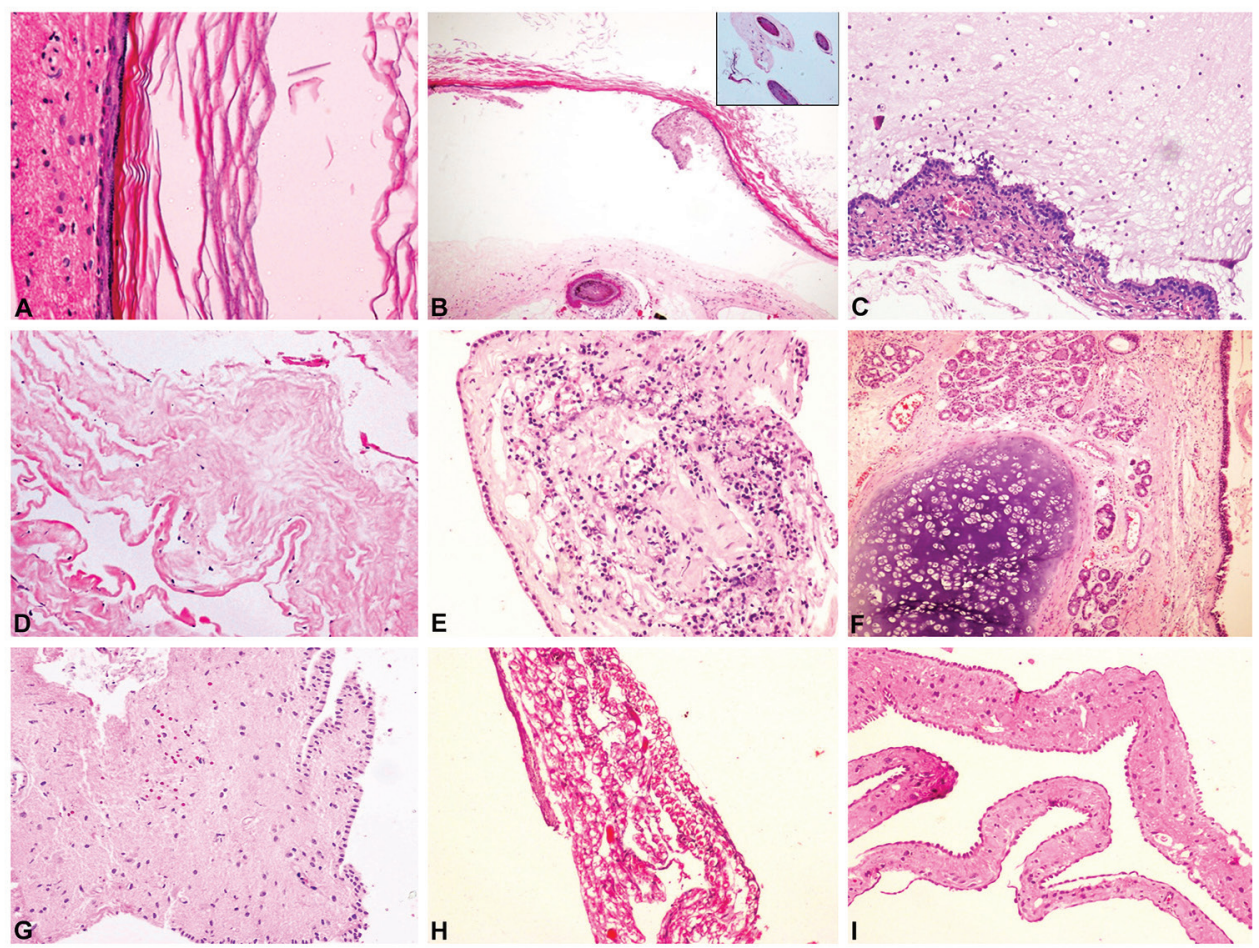

Fig. 1 Noninfective cysts: (A) epidermoid cyst with keratin flakes, $\mathrm{H}$ and E, $\times 40$, (B) dermoid cyst $(\times 4)$ with hair shaft in the inset $(\times 40)$, $\mathrm{H}$ and $\mathrm{E},(\mathrm{C})$ colloid cyst, $\mathrm{H}$ and E, $\times 20$, (D) arachnoid cyst, $\mathrm{H}$ and E, $\times 40$, (E) Rathke's cleft cyst with pituitary parenchyma in the wall, $\mathrm{H}$ and $\mathrm{E}, \times 10$, (F) neurenteric cyst, type B, H and E, ×4, (G) glioependymal cyst, $\mathrm{H}$ and E, $\times 20,(\mathbf{H})$ Tarlov's cyst, $\mathrm{H}$ and E, $\times 10,(\mathbf{I})$ porencephalic cyst, $\mathrm{H}$ and $\mathrm{E}, \times 4 . \mathrm{H}$ and $\mathrm{E}$, hematoxylin and eosin.

Neurenteric cysts were predominantly spinal (80.7\%) with cervical spine being the most common location, followed by thoracic spine. Of the five intracranial neurenteric cysts, two were located in the prepontine cistern, two in the fourth ventricle, and one in the cerebellopontine angle ( - Table 2 ). The mean age at presentation was 23.5 years with a male predilection (male:female ratio $=2.25: 1$ ). The cysts were lined by columnar epithelium and demonstrated the presence of mucin on PAS stains differentiating them from ependymal cysts. Of the 26 cases of neurenteric cysts, only two were 
group "B" neurenteric cysts, while the remaining were group "A" (24/26, 92.03\%) (-Fig. 1F).

There were 30 cases of Rathke's cleft cyst, all of which were in the sella-suprasellar location (mean age at presentation was 43.03 years and male:female ratio $=1: 1$; - Table $\mathbf{1}$ ). These cysts were lined by cuboidal to columnar epithelium similar to colloid cysts ( - Fig. 1E). They were differentiated from colloid cyst based on the location and presence of pituitary acini in the cyst wall. Seventeen of them (56.6\%) had the presence of pituitary acini in their walls. Five of them showed squamous metaplasia, while three of them revealed xanthogranulomatous response.

In the spine, Tarlov's cysts/perineural cysts constituted $(8 / 113) 7.07 \%$. Six were in the sacral region and two were in the lumbar spine (-Table 2 ). They occurred in older adults (mean age: 42.6 years) with a slight male predilection (male:female ratio $=1.6: 1$ ). They were characterized by the presence of nerve bundles in the cyst wall ( - Fig. 1H).

Of the three porencephalic cysts, two were present in temporal lobe and one in frontal lobe ( $\mathbf{- T a b l e ~} 2$; mean age at presentation - 21.3 years). Two patients were females, while one was a male. The histopathology was characterized by cyst wall with thin rim of gliotic neuroparenchyma with the cyst communicating with ependymal-lined ventricles (-Fig. 1I). They were covered by thickened meninges on the outer cortex. However, no history of trauma was elicited in these cases.

Less frequently encountered were glioependymal/ ependymal cysts (six) and glial cysts (four). The ependymal cysts were seen in infants and children whereas the glial cysts in adults (-Fig. 1G). There was a male preponderance noted in these lesions (male:female ratio $=2.3: 1$ ) $($ - Table 1 ).

Among the infective cysts, neurocysticercosis (42/49, $85.7 \%$ ) was the most common, followed by hydatid cysts (7/49, 14.2\%). Cysticercisus was commonly located in the hemispheres (20/42, 47.6\%), parietal lobe being most frequent followed by temporal lobe. The second most common location was ventricular system with the fourth ventricle harboring nine of them. Among the spinal cysticercosis, the dorsal spine was most frequently involved (-Table 3 ). The mean age at presentation was 33.8 years with a male:female ratio of 1.2:1. Among the 42 cases, 28 showed histopathological features of granular nodular stage of neurocysticercosis, seven were of nodular calcified stage, five were of vesicular stage (-Fig. 2A), and two were of vesicular colloidal stage. Seven cases showed lymphomononuclear inflammation surrounding these cysts, while four showed granulomatous host response.

Hydatid cysts (7/49, 14.28\%) were mainly hemispheric in location and frontal lobe followed by parietal lobe. Two

Table 3 Distribution of nonneoplastic infective central nervous system cysts

\begin{tabular}{|l|l|l|l|}
\hline Type of cyst & Total number of cases & Location & Number of cases \\
\hline Neurocysticercosis & 42 & & \\
\hline Intracranial & $35 / 42$ & Ventricular & 13 \\
\cline { 3 - 4 } & & Parenchymal & 20 \\
\cline { 3 - 4 } & & Suprasellar & 1 \\
\cline { 2 - 4 } & $7 / 42$ & Cerebellum & 1 \\
\hline Spinal & & Cervical & 3 \\
\cline { 3 - 4 } & & Thoracic & 2 \\
\cline { 2 - 4 } & & Lumbar & 1 \\
\cline { 2 - 4 } & 7 & Not specified & \\
\hline Hydatid cyst & $5 / 7$ & & 5 \\
\hline Intracranial & $2 / 7$ & Parenchymal & 1 \\
\hline Spinal & & Lumbar & \\
\hline
\end{tabular}
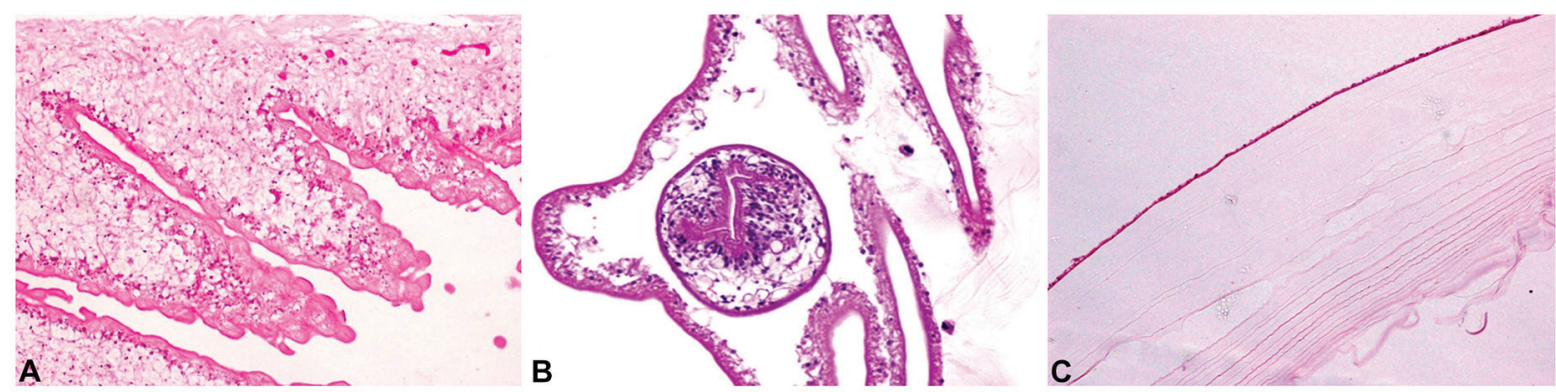

Fig. 2 Infective cysts: (A) cysticercal cyst, $\mathrm{H}$ and E, ×20, (B) hydatid cyst with scolex, $\mathrm{H}$ and E, ×20, (C) lamellated membranes of hydatid cyst, $\mathrm{H}$ and $\mathrm{E}, \times 20$. $\mathrm{H}$ and $\mathrm{E}$, hematoxylin and eosin. 
of the hydatid cysts were spinal in location (-Table 3 ). The age of the patients ranged from 10 years to 48 years (mean of 27.4 years) with a male:female ratio of $1: 1.3$. These were highlighted microscopically by the scolices and lamellated membranes (-Figs. 2B and C).

The study included 11 lesions which could not be further characterized due to the absence of specific features of any of the above cystic lesions, in particular, an indistinct lining.

\section{Discussion}

A wide variety of cystic lesions (nonneoplastic) can occur in the CNS. These are commonly detected on imaging. Although most of them are asymptomatic and incidentally detected, they may become symptomatic either because of pressure, rupture, or secondary inflammation. The most crucial features for exact typing include anatomic location and type of the lining of the cyst wall. Cystic lesions of CNS, both intracranial and spinal, show wide range of histomorphology. The noninfective nonneoplastic cysts are predominantly developmental in nature. The treatment and prognosis depend on the nature of the lesion; hence, histopathological characterization is mandatory.

The epidermoid cysts are derived from ectodermal rests. ${ }^{2}$ They may arise due to the failure of separation of the ectoderm from the underlying structures, that is the neural tube, which may occur as a result of embryologic accident between the third and fifth weeks of gestational life. In addition, they may be due to sequestration of the ectoderm or rarely due to implantation of the ectodermal tissue. They are more common in the intracranial rather than intraspinal location. In the present study, the ratio of intracranial to spinal epidermoids was 9.15:1 compared with 5:1 in the study by Sundaram et al. ${ }^{1}$ Cerebellopontine angle was the most common site in intracranial compartment similar to other studies. ${ }^{1,3,4}$ Two of the epidermoid cysts were located in the brainstem, which is an extremely uncommon location. ${ }^{1,5,6}$ Intraspinal epidermoid cysts are predominantly intradural and rarely intramedullary. ${ }^{1,3} \mathrm{We}$ did not encounter any intramedullary spinal epidermoid cysts.

Similar to epidermoid cysts, the dermoid cysts are also ectodermal in origin with a predilection for midline., ${ }^{1,3}$ Dermoids are predominantly intraspinal in contrast to epidermoid cysts ${ }^{1}$ as was seen in the present study. Both epidermoid and dermoid cysts are predominantly maldevelopmental, as a result of the inclusion of ectoderm during neural tube closure. The separation of neuroectoderm and its cutaneous counterparts occurs dorsally along the midline and thus explains their tendency to develop in midline. Laterally, situated lesions may be due to ectodermal inclusions during the formation of secondary otic and optic cerebral vesicles. ${ }^{5,7}$ The timing at which the embryologic accident that results in the failure of separation of neuroectoderm and cutaneous counterparts is said to occur prior to that of epidermoid cysts. They can also be acquired as a result of trauma or iatrogenic implantation of cutaneous tissue in the cranial or spinal space. ${ }^{5,8}$ However, none of our patients had a history of trauma.

The colloid cysts were the second most common cysts similar to reports by Sundaram et al and Din et al ${ }^{1,4}$ with a similar occurrence in the fourth decade. However, no age predilection was noted in the present study, in contrast to a study by Din et al ${ }^{4}$ The origin of colloid cysts is controversial. Studies indicate an endodermal origin rather than a neuroepithelial origin as they are immunohistochemically different from normal or neoplastic choroid epithelium. ${ }^{19,10}$

Arachnoid cysts were the third most common nonneoplastic cysts in the present study similar to the report by Din et al. ${ }^{4}$ The histogenesis of arachnoid cyst is unclear and is believed to be maldevelopment of the arachnoid membrane with subsequent dilatation. ${ }^{1,11}$ Unlike the studies by Sidhu et al and Din et $\mathrm{al}^{3,4}$ the most common location of arachnoid cysts in the present series was parenchymal, concordant with Sundaram et al ${ }^{1}$ study.

Rathke's cleft cysts are thought to have originated from remnants of Rathke's pouch. The incidence varies from 2 to $26 \%$ as seen in autopsy series. ${ }^{12,13}$ The present study included 30 cases of Rathke's cleft cyst constituting 5.6\% of all the nonneoplastic cysts of CNS. They are known to exhibit squamous metaplasia, and the present series had five cases with squamous metaplasia and three with xanthogranulomatous response.

The neurenteric cysts are mainly spinal in location and are usually associated with complex vertebral anomalies. The disruption in the process of closure of neurenteric canal and notochordal separation from primitive gut during the embryonal development leads to inclusion of the endodermal tissue with cyst formation. ${ }^{1,13}$ These cysts have been classified into three types by Wilkins and Odom. ${ }^{14}$ Group-A cyst is lined by a single layer of cuboidal or columnar epithelium with or without cilia. Group-B cysts have, in addition, the mucous glands and the smooth muscle. If ependymal or glial tissue is present in addition to features of group B, it is assigned as group C.

The present study included five intracranial neurenteric cysts along with 21 spinal neurenteric cysts. In our cohort, majority were group-A cysts (24/26, 92.3\%) and two of them were group-B. However, we did not encounter any group-C neurenteric cysts in our study. Three of these neurenteric cysts showed squamous metaplasia of the lining. One of the cases (L4) was associated with lipomyelomeningocele at a lower level (L5-S1).

The perineural cysts, also known as the Tarlov's cyst, most frequently occur in the sacral region. They occur in the perineural space between the pia and the perineurium formed by arachnoid..$^{15}$ They are usually located along the nerve roots. ${ }^{15,16}$ The present series included eight perineural cysts which were lumbosacral in location.

Porencephaly is a term used to describe a fluid-filled defect communicating with the ventricles or separated from them by a rim of brain tissue. It may occur as a result of maldevelopment or due to postnatal exposure to trauma, infection, or hemorrhage. ${ }^{17}$ 
The ependymal cysts are the neuroepithelial cysts lined by columnar or cuboidal epithelium and lack definite basement membrane and lie directly on the glial tissue. They are believed to have originated from displaced segments of neural tube. In contrast, the gliotic cysts lack the lining and are thought to be burnt out pilocytic astrocytoma. ${ }^{3}$ These together constituted $1.9 \%$ of all the cysts in our study.

Neurocysticercosis is due to infection of CNS by the pork tapeworm, Taenia solium. They were classified into intraparenchymal brain cysticercosis and extraparenchymal cysticercosis. ${ }^{18}$ These were considered as benign and malignant neurocysticercosis, respectively, by Estañol et al. ${ }^{19}$ They present at younger age with better prognosis. In contrast, the extraparenchymal neurocysticercosis occurs in the subarachnoid space and basal cisterns and is progressive. Neurocysticercosis involves four morphological stages, namely, vesicular stage which lacks inflammatory reactions, vesicular colloidal state wherein inflammation sets in, granular nodular stage where the parasite is dead and degeneration starts, and finally, the nodular calcified stage wherein the parasite and the capsule are retracted and calcified..$^{20}$

In the present study, there was one spinal neurocysticercosis which was intramedullary. Seven of them were in the calcified nodular stage.

Intracranial hydatid disease, which has an incidence of 1 to $2 \%$, is most frequently located in the supratentorial compartment. Intracranial hydatid cysts are usually solitary, and the route of spread is hematogenous. The parietal lobe was found to be most commonly involved in studies by Dharker et al and Balasubramaniam et $\mathrm{al}^{21-23}$ Spinal hydatidosis is even rarer and can involve any segment of the spine. ${ }^{24}$ Braithwaite and Lees have classified spinal hydatidosis based on the location into five subtypes. They are primary cyst in the cord, intradural cyst, extradural cyst, hydatid disease of the vertebrae, and paravertebral hydatid disease. ${ }^{25}$ The present series included five intracranial and two spinal hydatid cysts.

These cystic lesions may be confused with their mimickers on radiology, and the differentials vary depending on the site of the cysts. The cysts located in the pineal region may be confused with pineocytomas, while those located in the ventricles may mimic subependymomas and choroid plexus tumors on radiology. The neurocysticercal cysts may mimic abscess, tuberculomas, neoplasms (both primary and metastatic depending on the age of presentation), and other parasitic infections. ${ }^{26}$

\section{Conclusion}

A variety of cystic lesions occur in the CNS with overlapping clinical features, imaging findings, and cyst lining. The nonneoplastic cystic lesions have a wide spectrum of histopathology and in turn histogenesis. The understanding of the pathobiology helps in better management and prognosis of the patient. Recurrences of these lesions are usually due to incomplete surgical removal rather than a de novo occurrence.

These cysts have to be distinguished from cystic CNS neoplasms with a diminutive solid component. Hence, histological analysis plays a crucial role in the evaluation of these lesions, and the present study has attempted to give an overview/familiarity of the spectrum of the cystic lesions occurring in the CNS.

\section{Conflict of Interest}

None declared.

\section{Acknowledgments}

The authors would like to acknowledge Mr. Manjunath K, Department of Neuropathology, NIMHANS, for his assistance in pictorial montage.

\section{References}

1 Sundaram C, Paul TR, Raju BV, et al. Cysts of the central nervous system: a clinicopathologic study of 145 cases. Neurol India 2001;49(3):237-242

2 Fuller G, Ribalta T Dermoid cyst, epiderrmoid cyst, and dermal sinus. In: McLendon RE, Rosenblum MK, Bigner DD, eds. Russell and Rubinstein's Pathology of Tumors of the Nervous System. 7th ed. London: CRC Press; 2006:583-90

3 Sidhu M, Suri VS, Singh D, Tatke M, Kumar S. Histological analysis of cystic tumour like lesions of central nervous system. Indian J Pathol Microbiol 2002;45(1):7-14

4 Din NU, Arshad H, Ahmad Z, Hasan S, Bari ME. Symptomatic surgically treated non-neoplastic cysts of the central nervous system: a clinicopathological study from Pakistan. J Coll Physicians Surg Pak 2015;25(8):588-591

5 Obana WG, Wilson CB. Epidermoid cysts of the brain stem. Report of three cases. J Neurosurg 1991;74(1):123-128

6 Iihara K, Kikuchi H, Ishikawa M, Nagasawa S. Epidermoid cyst traversing the pons into the fourth ventricle. Case report. Surg Neurol 1989;32(5):377-381

7 Roux A, Mercier C, Larbrisseau A. Dube LJ, Dupuis C, Del Carpio R. Intramedullary epidermoid cysts of the spinal cord. Case report. J Neurosurg 1992;76(3):528-533

8 Lunardi P, Missori P. Supratentorial dermoid cysts. J Neurosurg 1991;75(2):262-266

9 Lach B, Scheithauer BW, Gregor A, Wick MR. Colloid cyst of the third ventricle. A comparative immunohistochemical study of neuraxis cysts and choroid plexus epithelium. J Neurosurg 1993;78(1):101-111

10 Tsuchida T, Hruban RH, Carson BS, Phillips PC. Colloid cysts of the third ventricle: immunohistochemical evidence for nonneuroepithelial differentiation. Hum Pathol 1992;23 (7):811-816

11 Rengachary SS, Watanabe I. Ultrastructure and pathogenesis of intracranial arachnoid cysts. J Neuropathol. Exp Neurol 1981;40(1):61-83

12 Voelker JL, Campbell RL, Muller J. Clinical, radiographic, and pathological features of symptomatic Rathke's cleft cysts. J Neurosurg 1991;74(4):535-544

13 Leech RW, Olafson RA. Epithelial cysts of the neuraxis: presentation of three cases and a review of the origins and classification. Arch Pathol Lab Med 1977;101(4):196-202

15 Tarlov IM. Spinal perineurial and meningeal cysts. J Neurol Neurosurg Psychiatry 1970;33(6):833-843

16 Andrieux C, Poglia P, Laudato P. Tarlov cyst: a diagnostic of exclusion. Int J Surg Case Rep 2017;39:25-28

17 Ryzenman JM, Rothholtz VS, Wiet RJ. Porencephalic cyst: a review of the literature and management of a rare cause of cerebrospinal fluid otorrhea. Otol Neurotol 2007;28(3):381-386

18 Garcia HH, Gonzalez AE, Gilman RH. Cysticercosis of the central nervous system: how should it be managed? Curr Opin Infect Dis 2011;24(5):423-427 
19 Estañol B, Corona T, Abad P. A prognostic classification of cerebral cysticercosis: therapeutic implications. J Neurol Neurosurg Psychiatry 1986;49(10):1131-1134

20 Dametto E. Histopathology of the human brain in neurocysticercosis. J Mol Histol Med Physiol 2016;1:106

21 Gupta S, Desai K, Goel A. Intracranial hydatid cyst: a report of five cases and review of literature. Neurol India 1999;47(3):214-217

22 Dharker SR, Dharker RS, Vaishya ND, Sharma ML, Chaurasia BD. Cerebral hydatid cysts in central India. Surg Neurol $1977 ; 8(1): 31-34$
23 Balasubramaniam V, Ramanujam PB, Ramamurthi B. Hydatid disease of the nervous system. Neurol India 1970;18(Suppl 1)-92-95

24 Pamir MN, Akalan N, Ozgen T, Erbengi A. Spinal hydatid cysts. Surg Neurol 1984;21(1):53-57

25 Braithwaite PA, Lees RF. Vertebral hydatid disease: radiological assessment. Radiology 1981;140(3):763-766

26 Osborn AG, Preece MT. Intracranial cysts: radiologic-pathologic correlation and imaging approach. Radiology 2006;239(3):650-664 